\title{
Enhancements to the NASA/Goddard Space Flight Center (GSFC) Space Environment Simulator (SES) Facility to Support Cryogenic Testing of the James Webb Space Telescope (JWST) Integrated Science Instrument Module (ISIM)
}

\author{
Paul Cleveland ${ }^{1}$ \\ Energy Solutions International L.L.C., Laytonsville, Maryland, USA, 20882 \\ Stuart Glazer ${ }^{2}$ and Edward Packard ${ }^{3}$ \\ NASA/Goddard Space Flight Center, Greenbelt, Maryland, USA, 20771
}

\begin{abstract}
NASA is the mission lead for the James Webb Space Telescope (JWST), the next of the "Great Observatories", scheduled for launch in 2014. It is directly responsible for the integration and test of the Integrated Science Instrument Module (ISIM), which includes a composite truss structure provided by NASA, and four science instruments sponsored and provided by NASA, the European Space Agency (ESA), the Canadian Space Agency (CSA), and the European Consortium (EC). Three of the four instruments are passively cooled and designed to operate at temperatures in the $36 \mathrm{~K}$ to $40 \mathrm{~K}$ range, and the fourth instrument is actively cooled to approximately $6 \mathrm{~K}$. The ISIM will undergo several performance tests at various levels of integration in the NASA Goddard Space Flight Center's (GSFC) Space Environment Simulator (SES), GSFC's largest thermal vacuum chamber. These activities range from Cryo-cycling the bare flight composite structure to thermal balance and performance testing of the full ISIM module. This paper describes the enhancements made to the SES chamber in order to support all cryogenic thermal vacuum testing of the ISIM. Upgrades discussed include: design and fabrication of a very large, removable and reconfigurable helium shroud; a new valve box permitting independent flow control of gaseous helium (GHe) to up to ten zones; and development of in-situ 3-dimensional photogrammetry capability in a cryogenic environment. Also presented will be select results from several facility tests already conducted to verify the chamber capabilities and optimize operational procedures, including the Helium Shroud -03 Configuration Acceptance Test, and the Helium Shroud -01 Configuration Chamber Certification Test.
\end{abstract}

\section{Introduction}

A. James Webb Space Telescope and the Integrated Science Instrument Module (ISIM)

The James Webb Space Telescope (JWST) is the next of the "great observatories", designed to be launched into orbit around the second Lagrange point in 2014. It has a $6.5 \mathrm{~m}$ (deployed) multi-faceted mirror, and its science instruments operate in short to medium wavelengths, to enable insights to the formation of the galaxies and planets following the "Big Bang". NASA's Goddard Space Flight Center (GSFC) is the mission lead, and is directly responsible for the Integrated Science Instrument Module (ISIM), including its integration and test. The suite of four science instruments, located in the cryogenic volume behind the primary reflector (denoted as Region 1), is comprised of the Near Infrared Spectrograph (NIRSpec), primarily sponsored by the European Space Agency (ESA) with substantial NASA contribution; the actively cooled Mid Infrared Instrument (MIRI), jointly sponsored by ESA

${ }^{1}$ James Webb Space Telescope Thermal Systems Engineer

${ }^{2}$ James Webb Space Telescope ISIM Thermal Systems Lead, Thermal Engineering Branch, Code 545.3

${ }^{3}$ NASA/GSFC, Lead Aerospace Engineer, Space Simulation Section, Code 549.0

1

American Institute of Aeronautics and Astronautics 
and the European Consortium (EC); the Fine Guidance Sensor (FGS), provided by the Canadian Space Agency (CSA); and the Near Infrared Camera (NIRCam), provided by NASA. In flight, NIRSpec, NIRCam, and FGS are cooled to the range of $36 \mathrm{~K}$ to $40 \mathrm{~K}$ passively via heat transfer through complex high-purity aluminum thermal links to dedicated radiators, while the MIRI is actively cooled to approximately $6 \mathrm{~K}$ using a cryocooler. NASA provides the cooler and supplemental hardware for MIRI. The cooler's compressor is located in the ambient temperature spacecraft bus, outside the cryogenic Region 1. The science instruments are mounted on the ISIM structure, a special invar and composite truss structure designed for exceptional optical stability, provided by NASA. The Observatory Prime Contractor is Northrop Grumman Aerospace Systems (NGAS).

Figures I-1 and I-2 illustrate the observatory and the major components of the ISIM, respectively. The ISIM Electronics Compartment (IEC), in close proximity to Region 1, houses the instrument and detector control electronics, and operates at approximately ambient temperature. It is denoted as "Region 2". The ISIM Harness Radiator (IHR), which operates below $80 \mathrm{~K}$ and is also provided by ISIM, rejects most harness parasitic heat loads to space before the harnesses enter Region 1. The ISIM thermal control subsystem provides 93 flight housekeeping temperature sensors on the instruments, ISIM structure, radiators, and other locations, and trim heaters to guarantee minimum instrument operational temperatures. It arranges for control of contamination control heaters on each instrument (except the MIRI), to avoid contamination during post-launch cooldown, and in the event of contamination on-station.

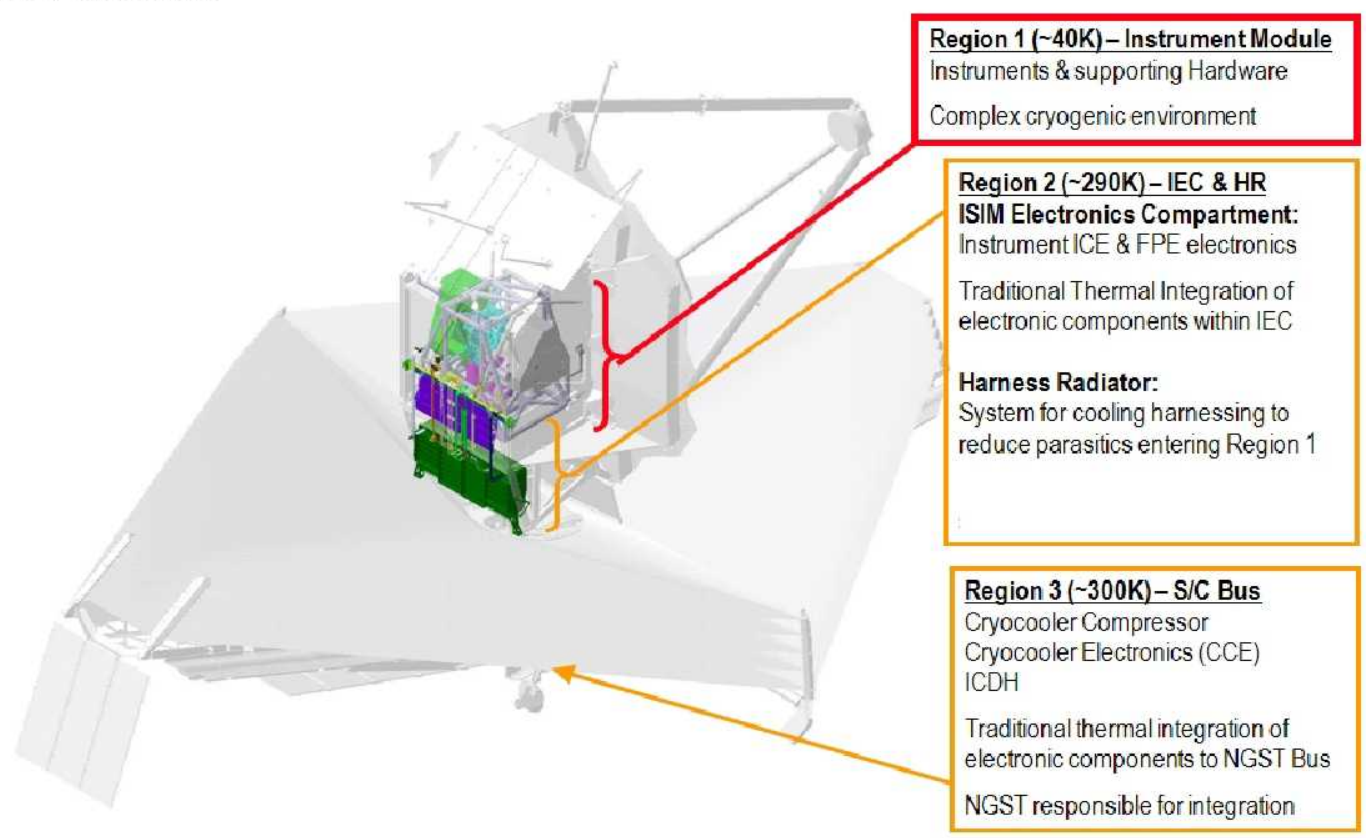

Figure I-1 JWST Observatory

Reference papers 1 and 2 provide a more comprehensive description of the JWST and ISIM.

\section{B. Thermal Verification and Testing Program}

Reference paper 3 describes the thermal verification and model validation plan that has been developed for JWST. The plan methodology consists of 1) judicious use of cryogenic and thermal design margin, 2) completely independent Observatory-level thermal model cross checks utilizing different analysis teams and software packages, and 3) a comprehensive set of thermal tests that occur at different levels of JWST assembly.

Since the entire JWST observatory is too large to be thermal vacuum tested in its deployed configuration, the final verification of the JWST Thermal Control System (TCS) will be performed by analysis. The tests that are conducted thus serve as key components or anchor points to verifying the performance of the entire JWST TCS prior to flight.

The overall test program is organized into three categories:

- Development Tests 
- Unit / Science Instrument Level Tests

- Element \& Observatory Level Thermal Tests

\section{Development Tests:}

The development test program includes all tests being performed on non-flight hardware to quantify the performance of key thermal design parameters. The goal of these tests is to reduce the risk of discovering performance issues in higher-level thermal tests where design modifications can have greater cost and schedule impact.

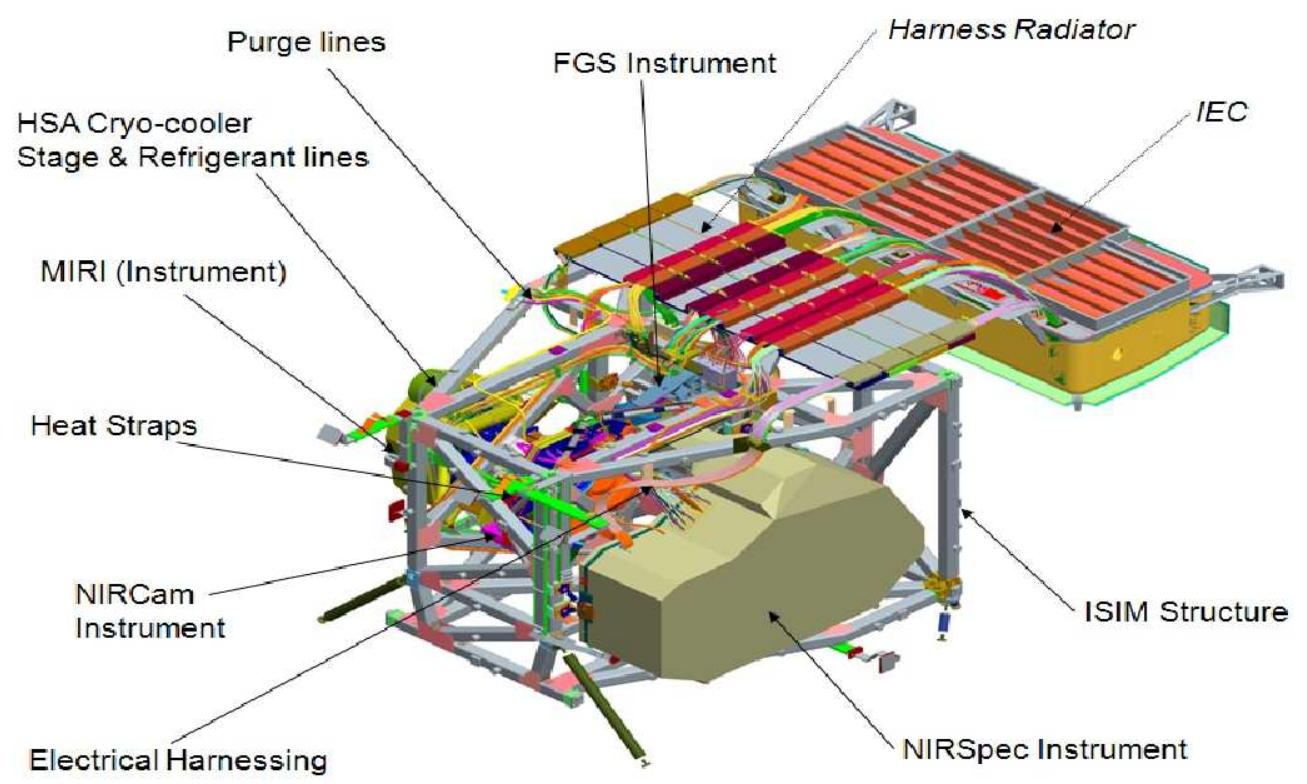

Figure I-2 Integrated Science Instrument Module, with Harness Radiator and Integrated Electronics Compartment

\section{Unit / Science Instrument Level Tests:}

The Science Instruments (SIs) undergo extensive thermal performance testing at component, Development Model (DM), Verification Model (VM), Engineering Test Unit (ETU), and Flight Model (FM) levels. In addition to measurements of power dissipation and dissipation stability, instrument thermal testing must quantify the isolation between the detector Focal Plane Arrays (FPAs) and the SI bench, and their sensitivity to transient heat loads caused by instrument operations, such as filter wheel and other mechanism usage, and calibration activities.

\section{Element \& Observatory Level Thermal Tests:}

Thermal testing of the complete deployed JWST Observatory is not possible due to the size of the sunshades and the widely varying thermal environments encountered by observatory elements. As a result, the final verification of the JWST thermal design relies on a series of individual element level thermal tests, followed by tests of multiple elements at combined levels of integration. Correlation and analysis of the thermal mathematical models occurs following each test.

The complement of Element Tests scheduled to take place in the Space Environmental Simulator (SES), also known as Facility 290, is shown in Figure I-3. The test sequence includes eight major tests, five of which contain flight hardware, with the other three serving to characterize the facility and key Ground Support Equipment (GSE). The eight major tests are:

1. The Helium Shroud -03 Configuration Acceptance Test. The test objectives were to validate the performance and to provide acceptance of the helium shroud in its Option 3 configuration (descriptions of the Option 01 and 03 shroud configurations are provided in section II). This configuration will be used for the Optical Telescope Element (OTE) Primary Mirror Backplane Support Structure (PMBSS) Test.

2. The Helium Shroud -01 Configuration Chamber Certification Test. The Chamber Certification test provided certification and performance verification of the Option 1 configuration prior to the CryoSet test.

3. The ISIM Protoflight Structure CryoSet Test. This test measures the optical alignment and stability of the (unloaded) Protoflight Structure at ambient, cryogenic operational, and extreme cold survival temperature 
conditions in-situ with the specialized photogrammetry equipment. The structure is exposed to a minimum of two thermal cycles from ambient to cold operational.

4. The ISIM Protoflight Structure CryoProof Test: This test verifies the ISIM structural integrity by taking the structure to extreme cold survival temperature conditions while loaded with dummy masses to simulate the flight instruments;

5. The OSIM Cryo-Cal Test. The OTE Simulator (OSIM) is the key optical GSE which will simulate light input to the instruments in ISIM-level testing. This test is designed to verify its optical performance at cryogenic conditions;

6. The OTE CryoSet test, which exposes the flight OTE backplane structure to thermal vacuum cycling from ambient to cryogenic temperatures;

7. Cryo-Vac Test \#1, the pre-vibration thermal vacuum and thermal balance testing of the flight ISIM;

8. Cryo-Vac Test \#2, the post-vibration thermal vacuum and thermal balance testing of the flight ISIM

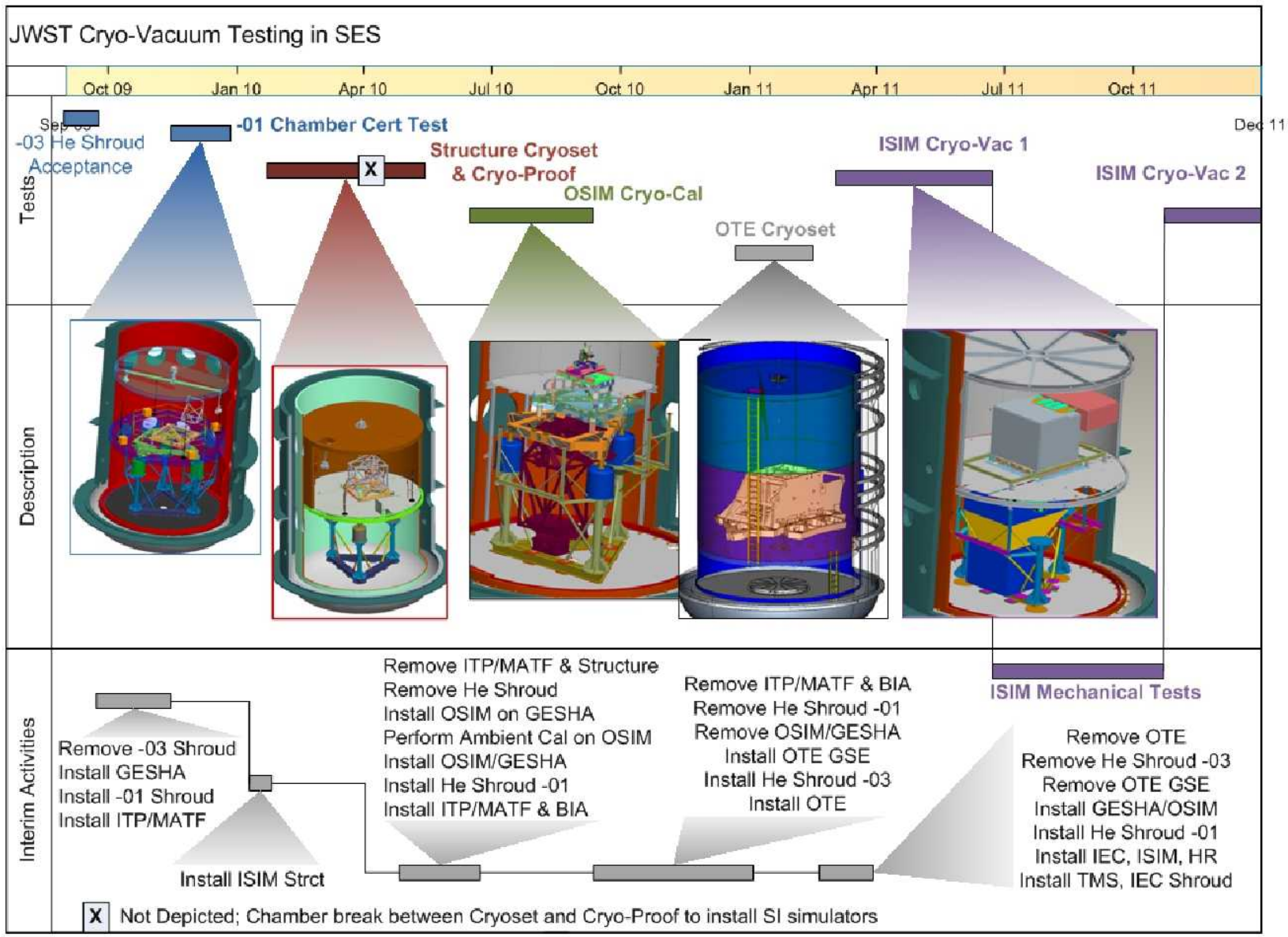

Figure I-3. JWST Cryo-Vacuum Tests in Space Environment Simulator at NASA Goddard Space Flight Center

\section{Space Environmental Simulator (SES) Facility and Enhancements}

The SES test chamber is a very large, vertically oriented cryopumped facility capable of achieving ultra low pressure and a wide range of thermal conditions. Figure II-1 shows the SES chamber facility. Key features of the facility include:

- Payload Volume: $27 \mathrm{ftD}$ x $40 \mathrm{ft} \mathrm{H}(8.3 \mathrm{~m} \times 12.3 \mathrm{~m})$

- Chamber evacuation provided by eight rotary piston mechanical pumps with Roots blowers, seven 48" (1.2 m) $30,000 \mathrm{l} / \mathrm{s}$ cryopumps, and one $6,000 \mathrm{l} / \mathrm{s}$ turbomolecular pump.

- Chamber pressure less than $5 \times 10^{-7}$ Torr $\left(6.67 \times 10^{-5} \mathrm{~Pa}\right)$ monitored with National Institute of Standards and Technology (NIST) traceable Granville-Phillips 370 Stabil-ION gauges. 
- Nitrogen Shroud Temperature Range:

- $\mathrm{GN}_{2}:+80^{\circ} \mathrm{C}$ to $-100^{\circ} \mathrm{C}$

$-\mathrm{LN}_{2}:-180^{\circ} \mathrm{C}$

- Helium Refrigerator: $1 \mathrm{~kW}$ cooling at $20 \mathrm{~K}$ (the refrigerator has been used in the past to support previous cryogenic tests, including the Wilkinson Microwave Anisotropy Probe (WMAP) spacecraft in 2001, but has only supplied the Gaseous Helium (GHe) to small, modular shrouds custom designed and fitted within the facility LN2 shroud)

- Air Filtration: 10,000 CFM, Class 10,000

- Resistance heater arrays, with external power supplies or gaseous nitrogen panels, are available for special thermal requirements.

- A thermoelectric quartz crystal microbalance (TQCM) and residual gas analyzer (RGA) provide both quantitative and qualitative monitoring of molecular contamination and gaseous constituents within the chamber.

- Closed circuit television coverage is available for monitoring the test article
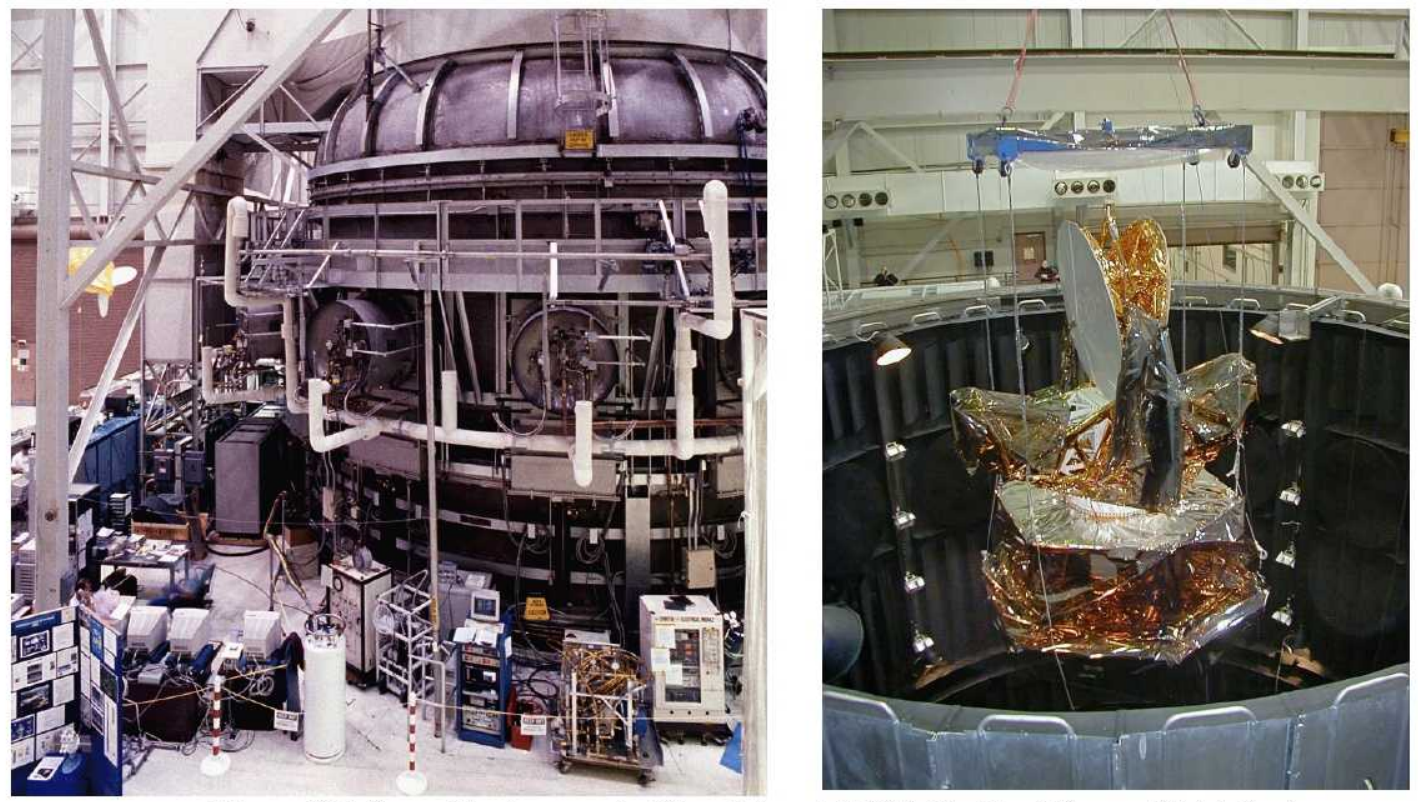

Figure II-1 Space Environmental Simulator at NASA Goddard Space Flight Center

Test articles are loaded through the top of the chamber using the Building 10 crane. Personnel entry is through a side opening access port. Two small viewports are located on the chamber side at different elevations. The chamber is used for thermal vacuum and thermal balance testing, and baking out very large test articles. A Class 10,000 clean anteroom provides personnel and small payload access to the chamber.

In support of the JWST test program, three additional major features were added to the SES facility:

1) Helium Shroud. This very large, removable and reconfigurable helium shroud is a major facility upgrade;

2) Valve Box. A helium valve box which permits independent flow control of gaseous helium to up to ten zones;

3) Photogrammetry System. This is a highly specialized dual camera system designed to precisely measure positional locations of hundreds of optical targets affixed to the ISIM structure and associated GSE, under cryogenic vacuum conditions.

These features are described in more detail below.

\section{A. Helium Shroud}

In support of the JWST testing at GSFC, a new removable and reconfigurable GHe shroud was designed and fabricated by DynaVac. For both the -01 and -03 configurations, it has a diameter of $7.62 \mathrm{~m}(25.5 \mathrm{ft})$, and fits within the existing fixed $\mathrm{LN}_{2}$ shroud which has a diameter of $8.23 \mathrm{~m}(27.0 \mathrm{ft})$. Figures II-2 and II-3 show the GHe shroud in two different height configurations which will be used for: (a) ISIM-level thermal vacuum/thermal balance 
(TV/TB) testing; and (b) Optical Telescope Element (OTE) hardware thermal testing, respectively. In configuration -01 , which supports the ISIM-level testing, the GHe shroud has an enclosed height of $4.57 \mathrm{~m}(15.0 \mathrm{ft})$. In configuration -03 , which supports the OTE test configuration, its enclosed height is $8.37 \mathrm{~m}(27.5 \mathrm{ft})$.

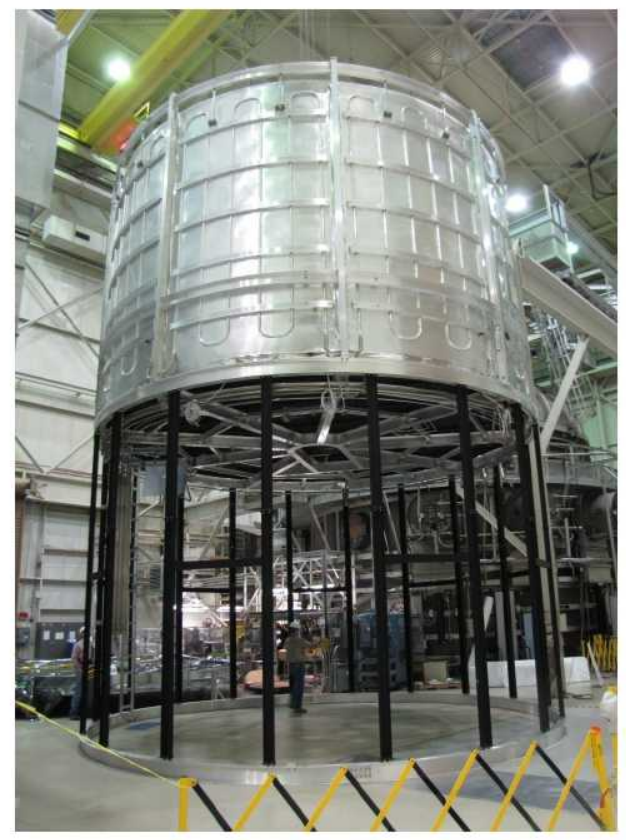

Figure II-2. SES GHe Shroud in -01 (ISIM) Test Configuration

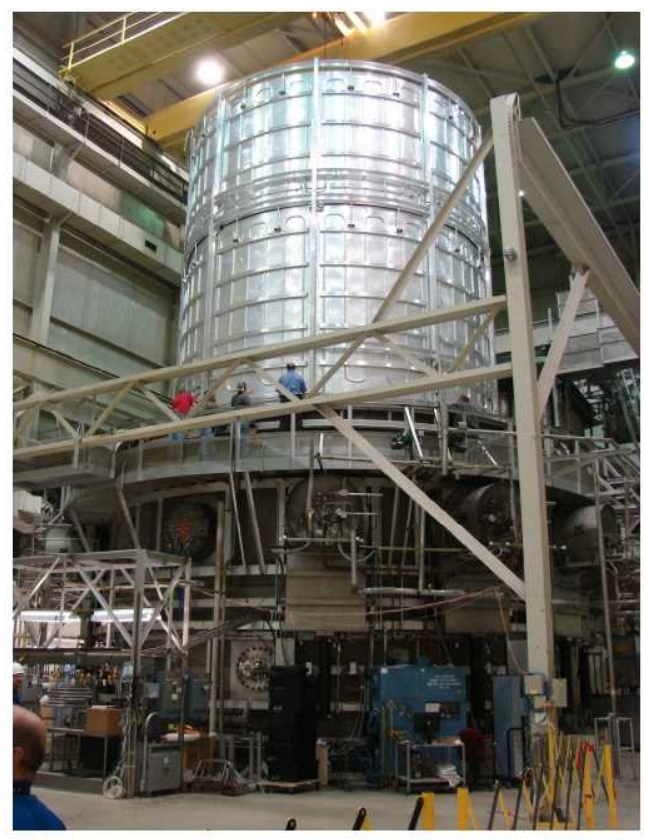

Figure II-3. SES GHe Shroud in -03 (OTE GSE) Test Configuration

\section{B. Valve Box}

An additional capability enhancement to the SES Helium Refrigeration System is a new valve box which permits independent flow control and tuning of GHe to up to ten zones. Five of the zones are used for control of the helium shroud; one for the roof, one for the floor, and three for the sides. The other five zones are available for active cooling of GSE or flight hardware. Features include vacuum jacketed lines between the valve box and helium refrigerator, valve control through the SES Supervisory Control and Data Acquisition (SCADA) system, and Programmable Logic Controller (PLC)/SCADA programming. Figure II-4 shows the valve box prior to and after installation.
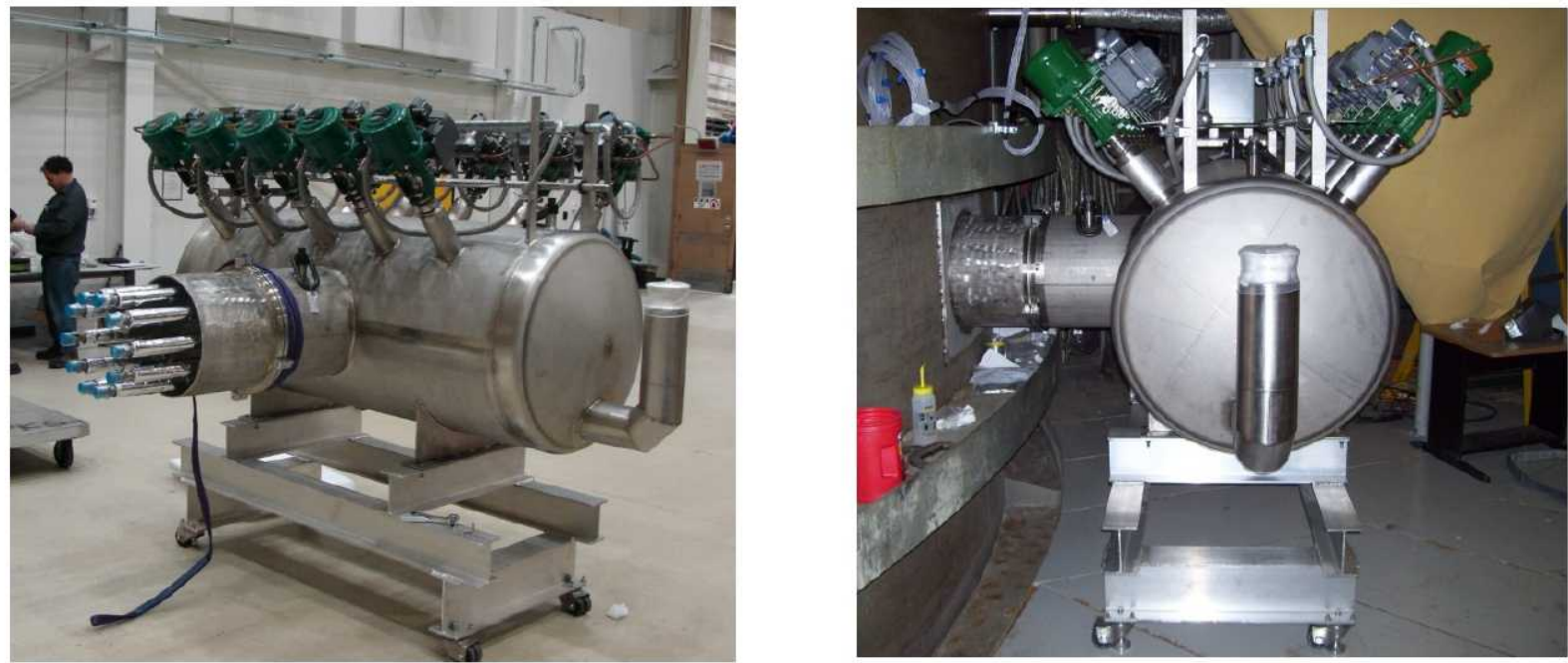

Figure II-4 Helium Valve Box Prior to and After Installation 


\section{Photogrammetry System Operating in a Cryogenic Environment}

The final major enhancement to the SES facility is the addition of a Photogrammetry (PG) system within the helium shroud volume.

Photogrammetry is a non-contact form of metrology which is used to measure warm-to-cold deformations in the ISIM structure and associated GSE within the helium shroud volume. Two custom INCA3 cameras, manufactured by Geodetic System, Inc. (GSI), are mounted into pressurized and thermally controlled canisters to maintain an ambient camera environment in the chamber. These canisters, in turn, are mounted to booms which revolve about the test article, providing geometrically diverse convergent camera stations.

Each canister assembly consists of a pressure vessel canister and He shroud separated by a thermal shield, as shown in Figure II-5. Two sets of ports containing sapphire windows, one set on the canister and one on the He shroud, allow the flash and camera to illuminate and image the test article. The cameras image retroreflective targets on the test article from various divergent camera stations in order to determine the location of the targets. Each camera rests on a rotation mechanism which allows the camera to roll 0 and 90 degrees inside the canister in order to perform in-situ self calibration. The PG cameras have been tested at GSFC and found to have a 2-sigma measurement uncertainty of $0.025 \mathrm{~mm}$. Figure II-6 shows the PG Camera with and without the canister and shroud. Figure II-7 shows the PG Camera and Boom Assembly mounted to helium shroud ceiling.

Reference papers 4 and 5 provide a more a comprehensive description of the use of photogrammetry on ISIM.

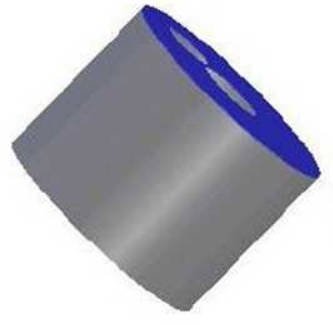

Thermal Shield 240K

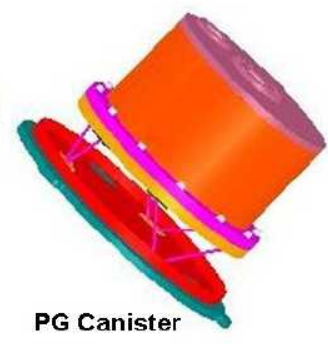

293K

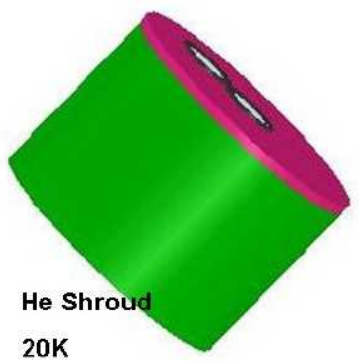

$20 K$

Figure II-5. Components of ISIM PG Canister System
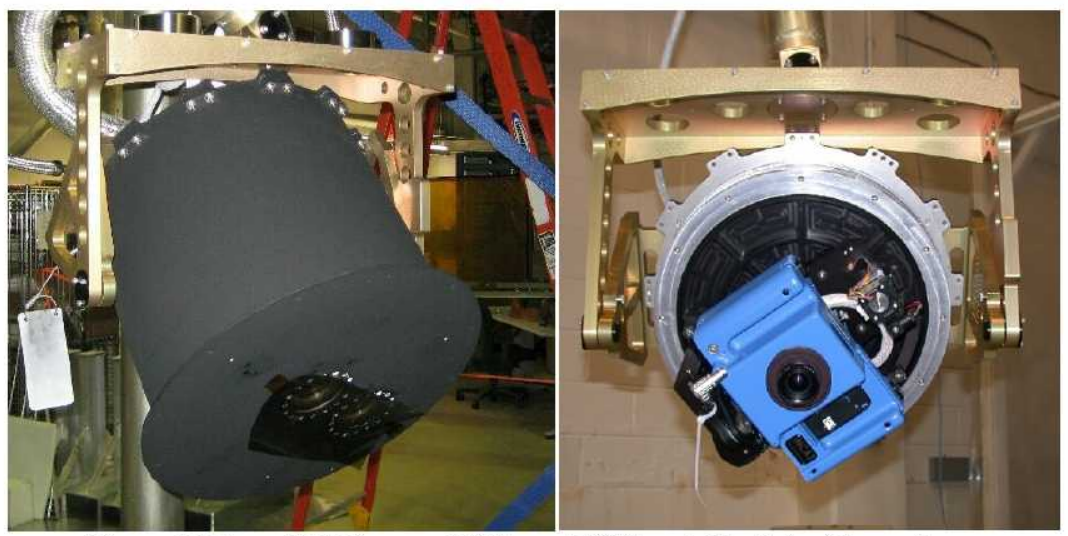

Figure II-6. PG Camera With and Without Canister/Shroud 

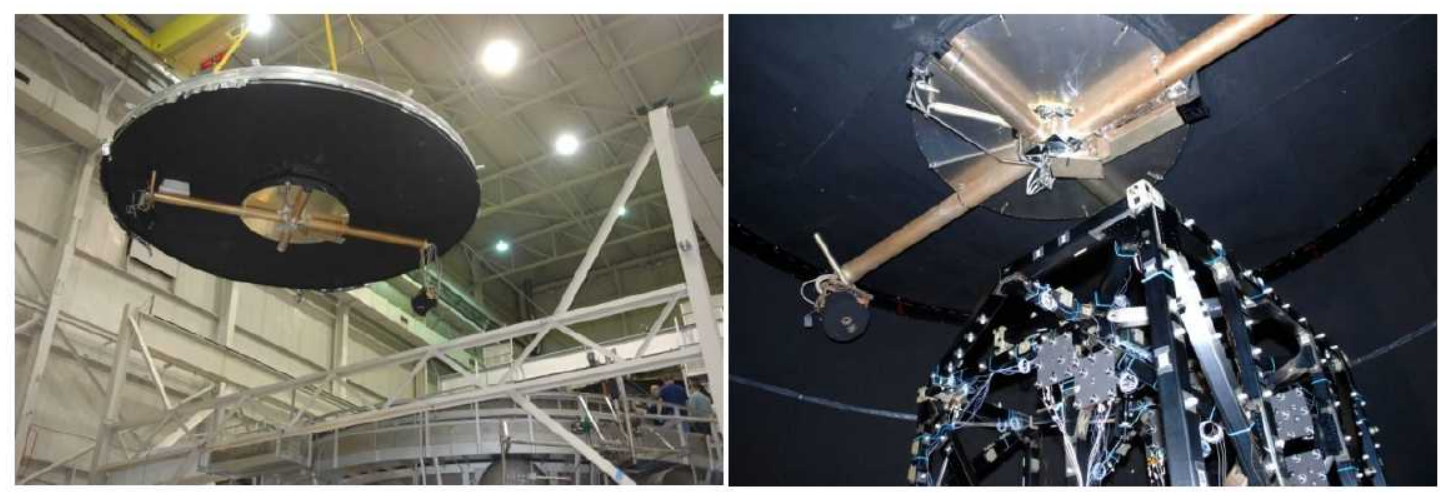

Figure II-7. PG Camera and Boom Assembly Mounted to Helium Shroud Ceiling

\section{Facility Performance Tests}

Prior to testing the flight hardware, two facility tests were conducted to incrementally check most aspects of the facility and GSE performance, verify the chamber capabilities, and optimize operational procedures. The two tests were a) the Helium Shroud -03 Configuration Acceptance test and b) the Helium Shroud -01 Configuration Chamber Certification Test.

\section{A. Helium Shroud -03 Configuration Acceptance Test}

The first facility test was the He Shroud Configuration -03 Acceptance Test in June 2009. The configuration reflected the larger He shroud configuration which will support the subsequent OTE CryoSet test. The purpose of the test was to provide validation and acceptance of the Helium Shroud design and of the performance specified in the Helium Shroud Specification, JWST-SPEC-008125. Heat lift characteristics of the refrigerator were measured by introduction of heat into the helium volume using a calrod heater assembly.

Specific test objectives included:

1) Verify that the SES can be evacuated to $5 \mathrm{E}-6$ Torr $\left(6.67 \times 10^{-4} \mathrm{~Pa}\right)$ in less than 15 hours.

2) Verify operation of the helium skid (remote operation, purifier, buffer tank, valves).

3) Verify there are no substantial helium shroud leaks (including helium line VCR connections) using RGA on chamber.

4) Determine the helium shroud cool-down time.

5) Verify Valve Box operation.

6) Verify helium shroud reaches $20 \mathrm{~K}$ with $\pm 6 \mathrm{~K}$ uniformity.

7) Verify the pressure drop across the helium shroud is $\leq 6 \mathrm{psid}$ (41368.5 Pa difference).

8) Quantify refrigerator heat lift capability versus temperature and Helium shroud parasitics (calrod test).

9) Control helium shroud at $27 \mathrm{~K}$ and $35 \mathrm{~K}$.

10) Validate all of the requirements listed in the requirements matrix.

11) SES chamber and helium shroud assembly depletion outgassing and rate background measurement

Figure III-1 shows the nominal acceptance test profile. Figure III-2 provides temperature results for key performance and control points. Figure III-3 shows the pressure drop across the helium shroud assembly. 


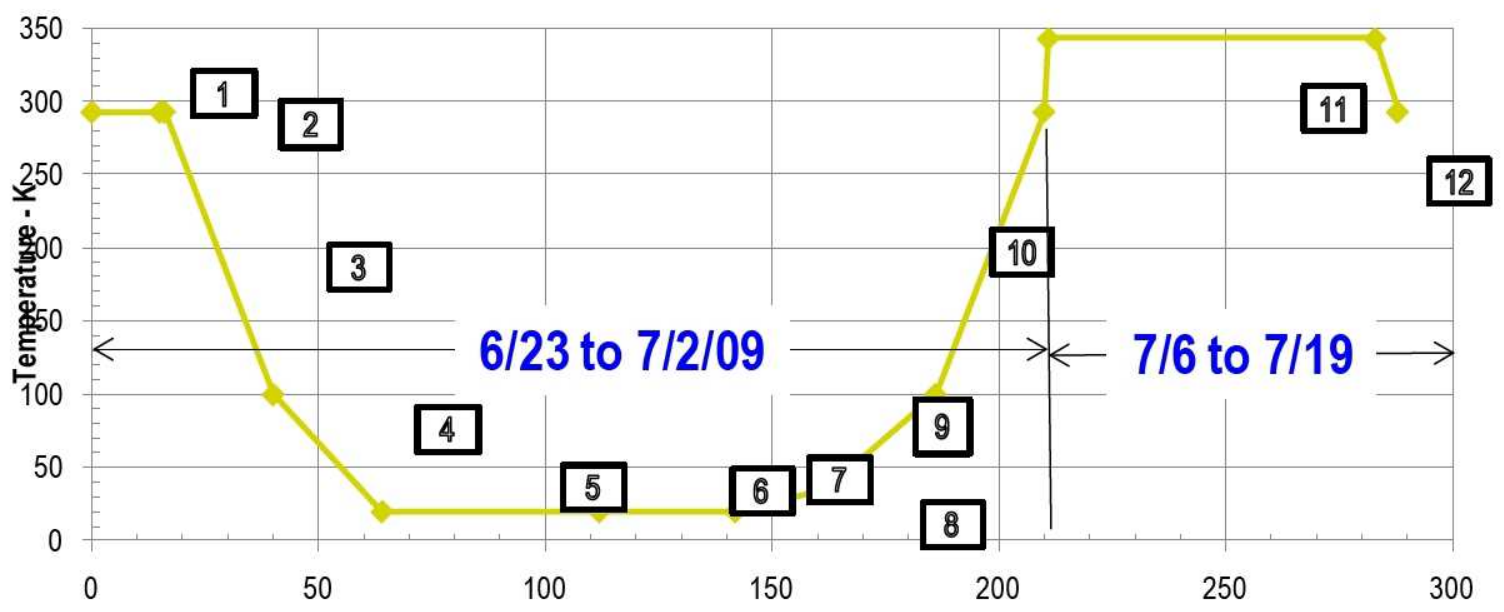

\begin{tabular}{|c|c|c|c|}
\hline \multicolumn{4}{|c|}{ Time - Hours } \\
\hline & Event & Temp & \\
\hline 1 & - Pumpdown & $293 \mathrm{~K}$ & \multirow[t]{2}{*}{ - Verify pressure via Micro lon Gage (MIG) < 5 e- 06 torr in 15 hours } \\
\hline 2 & - Check Leak Rate & $293 K$ & \\
\hline \multirow[t]{2}{*}{3} & - Flood LN2 shroud and guard shroud & $100 \mathrm{~K}$ & - Main chamber shroud and floor guard shroud \\
\hline & - Precool He shroud to $106 \mathrm{~K}$ & $100 \mathrm{~K}$ & -Without He turbine expander \\
\hline 4 & - Coal He shraud to $20 \mathrm{~K}$ & $20 \mathrm{~K}$ & - With He turbine expander \\
\hline 5 & $\begin{array}{l}\text { - Tune He shroud via valve box to meet } \\
+/-6 \mathrm{~K} \text { uniformity requirement }\end{array}$ & $20 \mathrm{~K}$ & - No heat load case \\
\hline \multirow[t]{2}{*}{6} & \multirow[t]{2}{*}{ - Performance Tests } & \multirow[t]{2}{*}{$20 K$} & - Actuate calrods $250 \mathrm{~W}, 500 \mathrm{~W}, 700 \mathrm{~W}$ \\
\hline & & & $\begin{array}{l}\text { - Tune He shroud via valve box to meet }+/-6 \mathrm{~K} \text { uniformity } \\
\text { requirement }\end{array}$ \\
\hline 7 & \multirow[t]{2}{*}{ - Contral Shroud } & $27 \mathrm{~K}$ & - Secure Calrads (Turn off) and control shroud to $27 \mathrm{~K}$ \\
\hline 8 & & $35 K$ & - Control to $35 \mathrm{~K}$ \\
\hline 9 & - Return shroud to LN2 Temperatures & $100 \mathrm{~K}$ & - Controlled fashion $(3 \mathrm{~K} / \mathrm{Hr})$ \\
\hline 10 & $\begin{array}{l}\text { - Return shroud to Ambient } \\
\text { Temperatures }\end{array}$ & $293 K$ & - Controlled fashion \\
\hline 11 & $\begin{array}{l}\text { - Warm environment to }>323 \mathrm{~K} \text { and } \\
\text { perform depletion bakeout }\end{array}$ & $>323 K$ & $\begin{array}{l}\text { - Bakeout until TQCM Delta-delta }<10 \mathrm{~Hz} / \mathrm{Hr} / \mathrm{Hr} \text { for } 4 \text { consecutive } \\
\text { hours while the Shroud is at }>323 \mathrm{~K} \text { and the } \mathrm{QCM} \text { is collecting at - } \\
30 \mathrm{C}\end{array}$ \\
\hline 12 & - Outgassing rate measurement & $298 \mathrm{~K}$ & - An outgassing rate measurement in $\mathrm{Hz} / \mathrm{hr}$ \\
\hline
\end{tabular}

Figure III-1. JWST -03 Acceptance Test Profile 


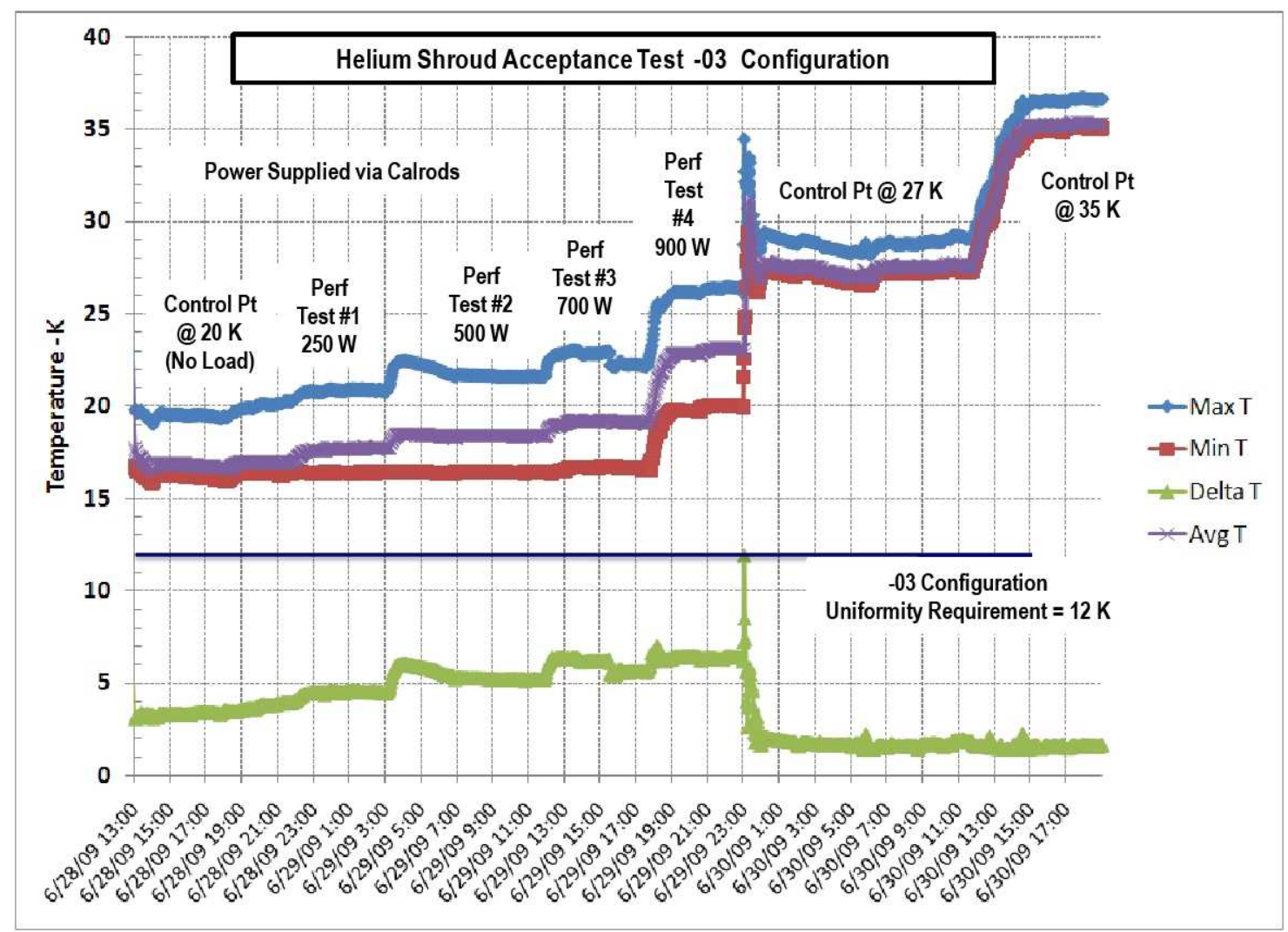

Figure III-2. JWST -03 Acceptance Test: Test Temperature Results for Key Performance and Control Points

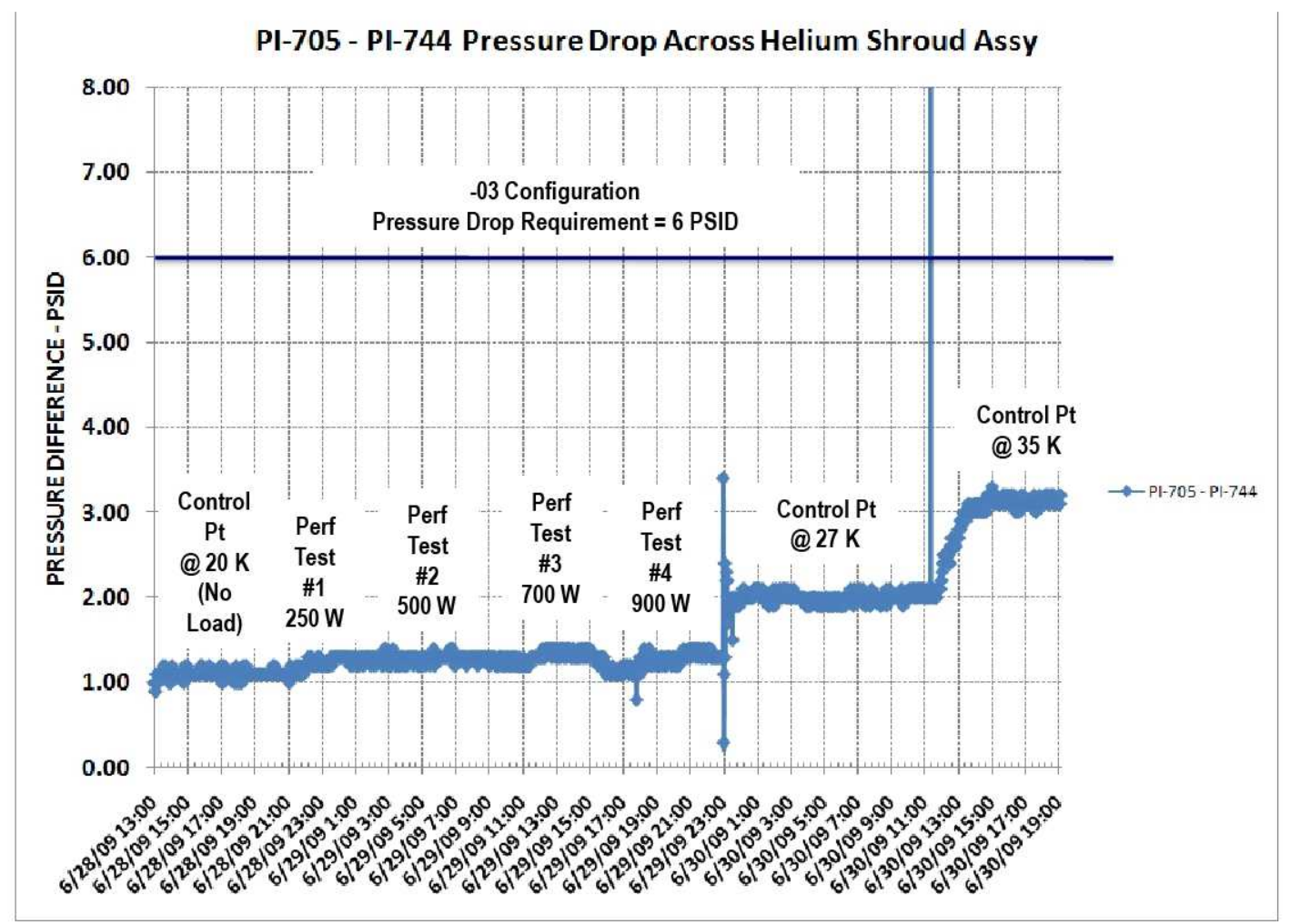

Figure III-3. JWST -03 Acceptance Test: Pressure Drop Across Helium Shroud Assembly

10

American Institute of Aeronautics and Astronautics 
Test results were excellent, confirming adequate helium refrigerator heat lift capacity, reliability, shroud temperature stability and gradient control, and vacuum retention. The shroud acceptance was completed via compliance with all test requirements. Useful observations included an assessment of the parasitic heat load at a level of $304 \mathrm{~W}$ (in the $250 \mathrm{~W}$ performance point case). The parasitic heat load was calculated by taking the enthalpy of gas returning to the cold box and subtracting from it the enthalpy of the helium gas at the cold box supply and multiplying this difference by the estimated helium gas mass flow rate. From this heat load, the measured calrod heater power was subtracted.

In addition, the test yielded over 17 specific lessons learned and comments which served as invaluable inputs into the next test. These included:

1) The gas management valves (Mass In and Mass Out) valves should be controlled off of the compressor discharge pressure values rather than the suction pressure to minimize pressure swing oscillations

2) The speed sensor cable for the turbine should be replaced.

3) The pressures displayed on the control screen should be in the units of PSIA (Pounds per Square Inch Absolute) since the helium refrigeration process is based on gas at absolute conditions. (No action taken).

4) The current PLC based control system should be further programmed to perform complete data acquisition functions. (Code 549 completed this.)

5) There is still a small chamber leak which is not allowing the chamber base pressure not to go below $2 \times 10-7$ torr $(2.67 \mathrm{e}-5 \mathrm{~Pa})$. The RGA history should be analyzed to determine if the suspect leak is air or nitrogen. Additional turbo pumps may be required if a lower base pressure is required. (The SES chamber and helium shrouds were thoroughly leak-checked prior to the next test.)

6) Whenever the helium skid control is lost, the temperature of the helium shroud will increase abruptly. This was experienced after powering off the $900 \mathrm{~W}$ load and transitioning the skid to $27 \mathrm{~K}$. The chamber pressure quickly rose two decades when the shroud increased about $10 \mathrm{~K}$. That could be a contamination issue as well as a thermal problem. The generator is not capable of providing enough power to back up the helium compressor, which is a $150 \mathrm{hp}$ motor, during a power outage! (Improvements were made to the helium skid operating procedure and the gas management system to reduce the probability of dropping the skid and bringing it back on line quickly if it is dropped.)

7) There is a concern about heater power resolution for the cal rods. They were using room temperature resistance and calculating power using $\mathrm{I}^{\wedge} 2 \mathrm{R}$. Future tests will require four wire measurements. (Calrod resistance vs temperature is well understood (roughly $3 \%$ between $20 \mathrm{C}$ and $300 \mathrm{C}$ ). Calrod temperatures were measured with Type $\mathrm{K} \mathrm{T} / \mathrm{Cs}$ (accuracy $\pm 2.2 \mathrm{C}$ or $\pm 0.75 \%$ ).)

8) Temperature resolution is also an issue. Only $0.010 \mathrm{~K}$ increments were being logged for this test. Future tests need better resolution. There was also an issue with the break point information used to convert the voltages to temperature by the Agilent data system. That should be resolved before the next test. (The silicon diodes on the helium shroud are standard curve with $\pm 0.5 \mathrm{~K}(2 \mathrm{~K}$ to $100 \mathrm{~K})$ tolerance. The break points were refined during the acceptance test.)

9) Change the mass controller process variable to the compressor discharge pressure instead of the suction side. This will greatly reduce the risk of a system shutdown due to high brake pressure or low bearing pressure. This controller should also have a user adjustable dead-band to enhance system stability during thermal balance phases.

10) Modify the system to display silicon diodes with 0.1 degree resolution and 0.01 on the TIC-712 $1000 \mathrm{~W}$ return heater. This is critical to control stability and to the accuracy of Q calculations needed by Paul C. The diodes have the resolution so we need to take advantage of the information. (Code 549 to implement.)

11) Re-locate the TI-705 expander outlet diode to a location downstream of V-724. This one is not critical but useful during operation above $20 \mathrm{~K}$. (Code 549 is evaluating.)

12) Staff members had to go into the PLC logic to force some coils just to keep the thermal system running. It is understood that the vacuum and thermal PLC's were recently consolidated and some bugs are to be expected. It is believed that there is a serious Modbus Plus network latency issue that has to be resolved before any flight testing resumes. The way the system was behaving, the unforeseen problems are risky. (Code 549 to upgrade current software version of GE Fanuc Proficy HMI/SCADA iFIX software from version 3.5 to 5.0 .)

13) Facilities should review the system interlocks and remove any that they feel are unnecessary. For instance, if there is a short power hit and the system loses process water for a minute. Do we really want the main valves to close and lose vacuum? The compressors protect on over-temp already. (Code 549 to add three minute timers to delay loss of cryopumps due to momentary power outage causing water loss.) 
14) Maintenance and upgrades were performed on the helium skid that probably introduced water vapor into the system. (Code 549 to verify added compressor oil is free of water with a hygrometer, verify absorber (changed every 2000 hours) is thoroughly dry with a hygrometer, add hygrometer checks to maintenance procedures)

15) When the helium skid purifier gets saturated it takes over 12 hours to warm the helium skid cold box to purge the system. (Code 549 to evaluate adding a heater inside the cold box or add purifier).

16) The purchased purifier was not utilized because the location of the quick disconnects was not effective to purify the helium gas stream. (Code 549 to obtain an estimate to weld in two Ts and three valves between the third coalescer and the absorber. This location is ideal for drying the system gas without contaminating the absorber. Purifier will be valved out during cryogenic operations. Add purifier operation to helium skid operating procedure.)

17) The helium skid precooling was not started until the chamber shroud was cooled causing a greater delay in the helium shroud cool down than necessary. (Code 549 to change the procedure to start helium skid precooling when chamber is evacuated.)

\section{B. Helium Shroud -01 Configuration Chamber Certification Test}

The second facility test was the SES Chamber Hardware Certification Test in early 2010 which used the smaller -01 helium shroud configuration.

This test allowed evaluation of planned test procedures; adequacy of the thermal control hardware affixed to critical GSE; operational performance characterization of the specialized photogrammetry equipment and its thermal control system; and dimensional alignment stability of the critical ISIM Test Platform (ITP), used to support the flight ISIM in test.

Specific test objectives included:

1) SES Chamber and GSE outgassing rate background measurement

2) ISIM Test Platform (ITP) Performance Verification Test

3) PG Characterization Test

4) Demonstrate ability to inject and control He exchange gas

5) Perform $\mathrm{He}$ effect on MLI experiment

6) Helium shroud -01 characterization

7) Emergency Power Shutdown Test

Figure III-4 shows the chamber certification test configuration. Figure III-5 provides the test profile. Shown in Figure III-6 are the average nitrogen shroud temperature in blue, the average helium shroud temperature in purple, the average ITP temperature in red, and the chamber pressure (opposite scale) in green. 


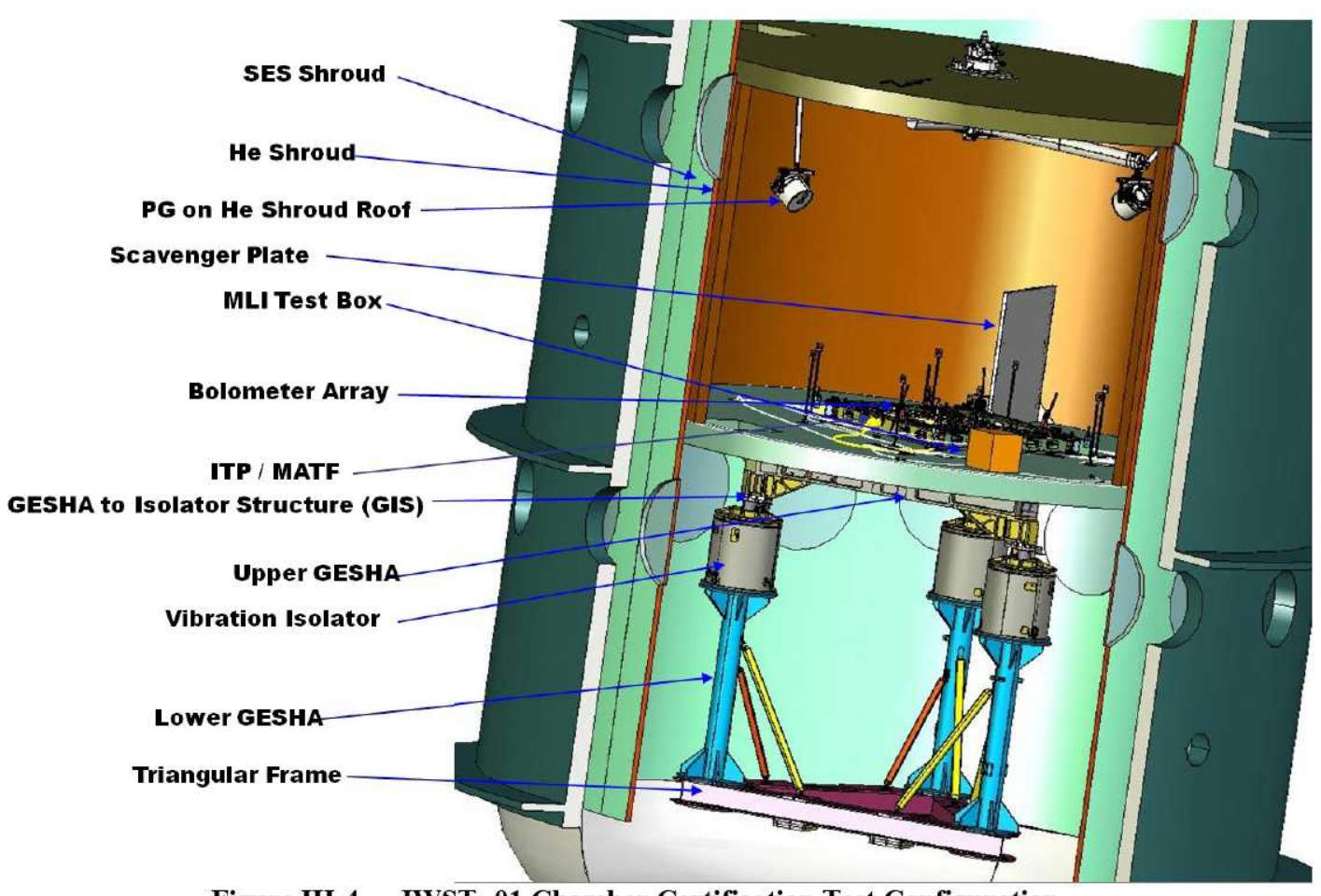

Figure III-4. JWST -01 Chamber Certification Test Configuration

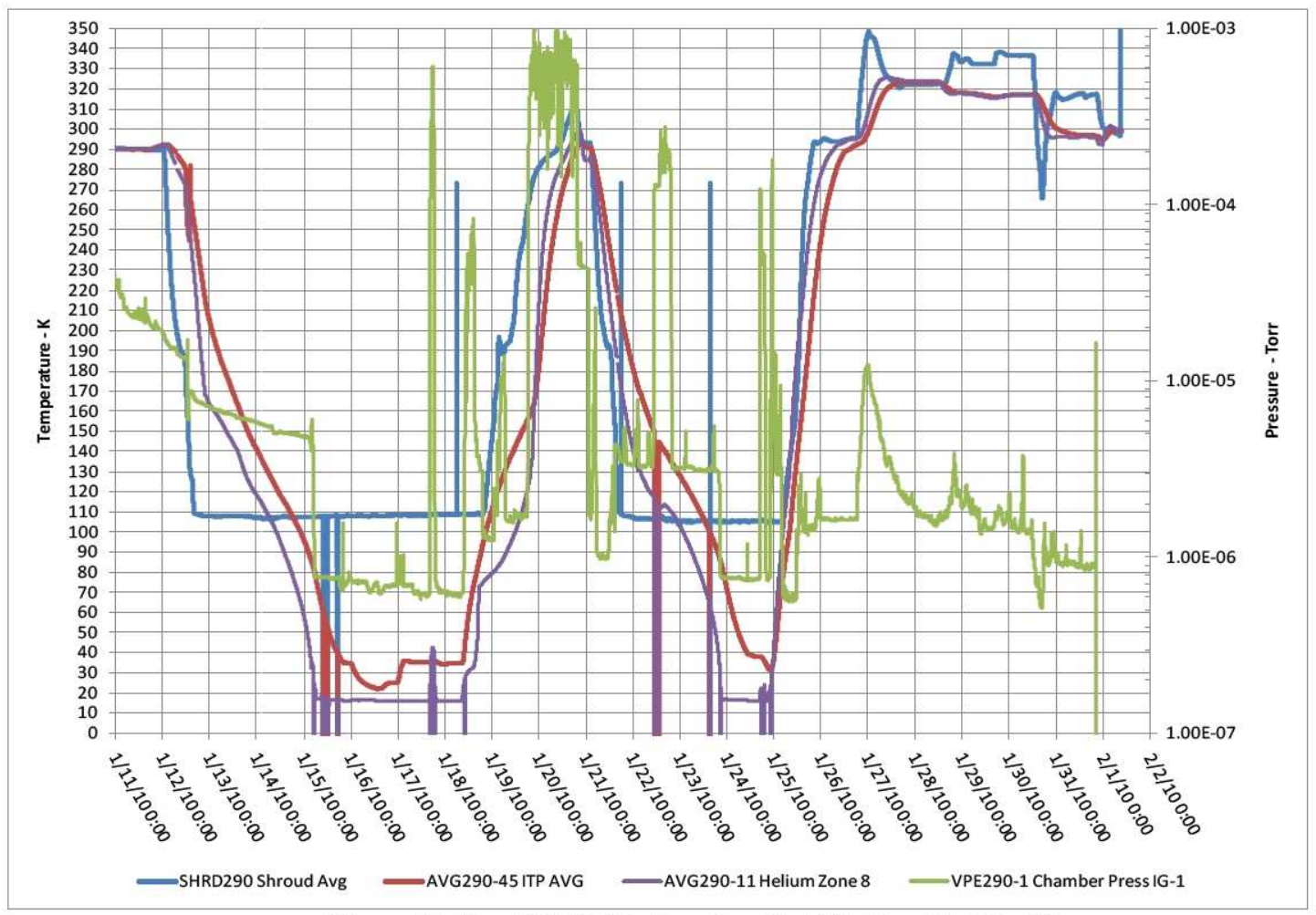

Figure III-5. JWST -01 Chamber Certification Test Profile 


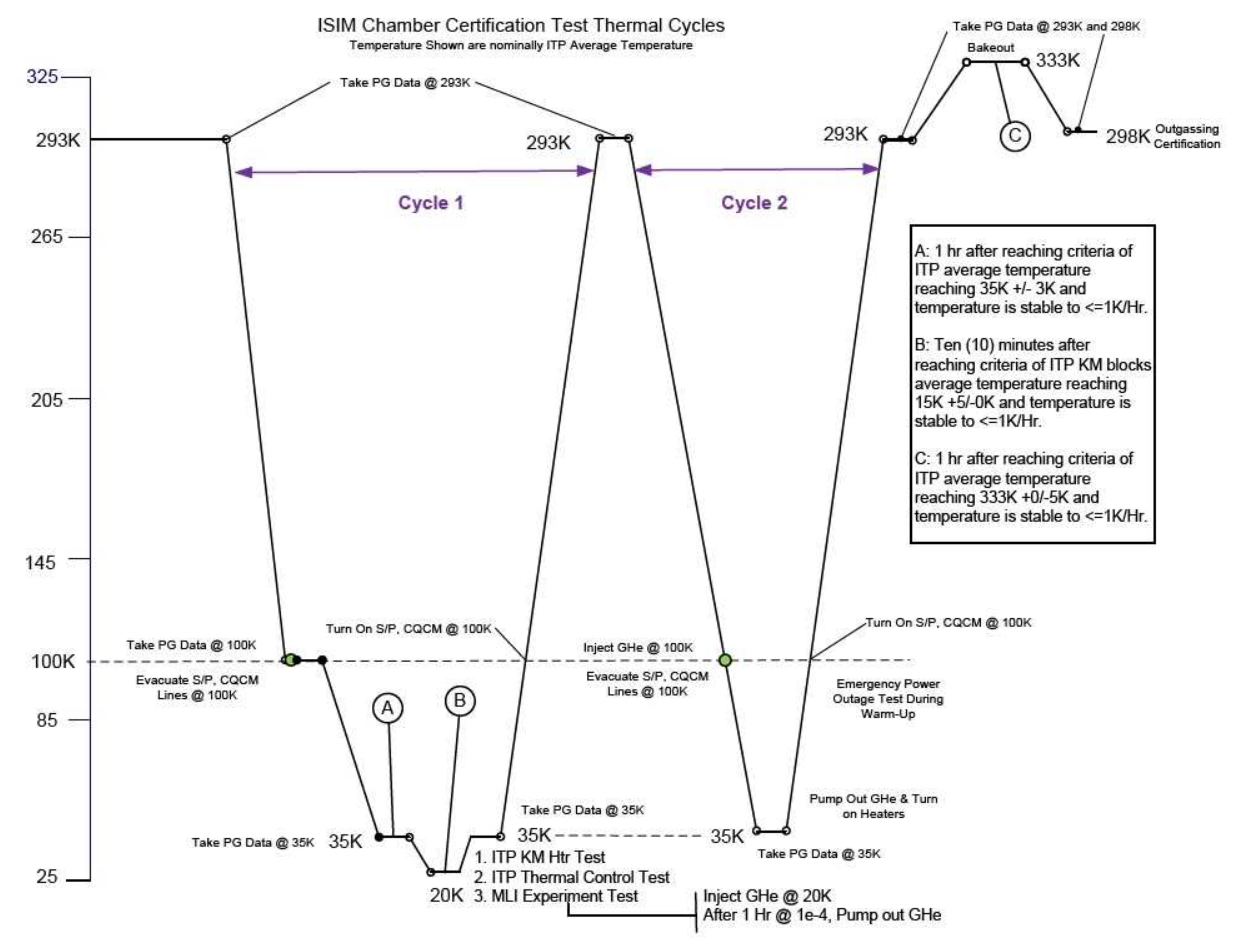

Figure III-6 JWST -01 Chamber Certification Select Pressure and Temperature Results

Thermal test results were excellent. The PG thermal design proved to be robust and adequate to protect the cameras. The ITP thermal control was adequate to meet all thermal requirements. The Upper and Lower Goddard Equipment Support Hardware Assembly (GESHA) thermal requirements were satisfied. One area of surprise occurred during the use of Free Molecular Heat Transfer (FMHT) at 2e-4 Torr $\left(2.67 \times 10^{-2} \mathrm{~Pa}\right)$ and a payload temperature of $100 \mathrm{~K}$. At these conditions, the helium refrigerator capacity was overwhelmed. The resulting thermal recommendations were to: 1) add a vertical Vapor Deposited Aluminum (VDA) curtain (VDA-2) between the helium shroud and nitrogen shroud to reduce the radiative and FMHT coupling; 2) inject gaseous helium directly into the helium shroud volume instead of behind the nitrogen shroud in order to assist the ISIM structure cooldown from $100 \mathrm{~K}$ to $35 \mathrm{~K}$; and 3) locate and repair nitrogen shroud "cold" leaks that become apparent when the shroud is cooled to $\mathrm{LN}_{2}$ temperature.

\section{Conclusion}

The enhancements made to the SES chamber to support cryogenic thermal vacuum testing of the OTE/PMBSS and ISIM were successful. The Helium Shroud -03 Configuration Acceptance Test and the Helium Shroud -01 Configuration Chamber Certification Test demonstrated that both helium shroud configurations met or exceeded all JWST test requirements. The design and fabrication of the very large, removable and reconfigurable helium shroud was effective. The valve box successfully permitted independent flow control of GHe to five helium shroud zones and up to five auxiliary zones. Development of in-situ 3-dimensional photogrammetry capability inside the cryogenic -01 Configuration helium shroud was also successfully demonstrated. Both the -01 and -03 helium shroud configurations demonstrated their ability to successfully perform JWST OTE/PMBSS and ISIM cryogenic tests.

CSA Canadian Space Agency

DM Development Model

EC European Consortium

ESA European Space Agency

\author{
Appendix - Acronyms \\ MATF Master Alignment Test Fixture \\ MIRI Mid Infrared Instrument \\ MLI Multilayer Insulation \\ NGAS Northrop Grumman Aerospace Systems
}

14

American Institute of Aeronautics and Astronautics 


$\begin{array}{ll}\text { ETU } & \text { Engineering Test Unit } \\ \text { FGS } & \text { Fine Guidance Sensor } \\ \text { FM } & \text { Flight Model } \\ & \\ \text { FMHT } & \text { Free Molecular Heat Transfer } \\ \text { FPA } & \text { Focal Plane Arrays } \\ \text { GESHA } & \text { Goddard Equipment Support Hardware } \\ & \text { Assembly } \\ \text { GHe } & \text { Gaseous Helium } \\ \text { GIS } & \text { GESHA to Isolator Structure } \\ \text { GN } & \text { Gaseous Nitrogen } \\ \text { GSE } & \text { Ground Support Equipment } \\ \text { GSFC } & \text { Goddard Space Flight Center } \\ \text { GSI } & \text { Geodetic System, Inc. } \\ \text { IEC } & \text { ISIM Electronics Compartment } \\ \text { IHR } & \text { ISIM Harness Radiator } \\ \text { ISIM } & \text { Integrated Science Instrument Module } \\ \text { ITP } & \text { ISIM Test Platform } \\ \text { JWST } & \text { James Webb Space Telescope } \\ \text { LN } & \text { Liquid Nitrogen }\end{array}$

\begin{tabular}{|c|c|}
\hline NIRCam & Near Infrared Camera \\
\hline NIRSpec & Near Infrared Spectrograph \\
\hline NIST & $\begin{array}{l}\text { National Institute of Standards and } \\
\text { Technology }\end{array}$ \\
\hline OSIM & OTE Simulator \\
\hline OTE & Optical Telescope Element \\
\hline PG & Photogrammetry \\
\hline PLC & Programmable Logic Controller \\
\hline PMBSS & Primary Mirror Backplane Support Structure \\
\hline PSIA & Pounds per Square Inch Absolute \\
\hline RGA & Residual Gas Analyzer \\
\hline SCADA & Supervisory Control and Data Acquisition \\
\hline SES & Space Environmental Simulator \\
\hline SI & Science Instruments \\
\hline TCS & Thermal Control System \\
\hline TQCM & Thermoelectric Quartz Crystal Microbalance \\
\hline VDA & Vapor Deposited Aluminum \\
\hline VM & Verification Model \\
\hline WMAP & Wilkinson Microwave Anisotropy Probe \\
\hline
\end{tabular}

\section{Acknowledgments}

P.C. Author would like to thank Mr. D. McGuffey for use of graphics of test plans, Mr. S. Thomson for graphics illustrating ISIM flight and corresponding test configurations, and Mr. B. Comber and Mr. B. Bell for preliminary thermal analysis results.

\section{References}

${ }^{1}$ Parrish, K., Glazer, S., Thomson, S., "The Cryogenic Thermal System Design of NASA's James Webb Space Telescope (JWST) Integrated Science Instrument Module (ISIM)", ICES Conference, Paper 05ICES-206, 2005

${ }^{2}$ Glazer, S., Cleveland, P., "James Webb Space Telescope Integrated Science Instrument Module Thermal Balance/Thermal Vacuum Test Configuration and Test Planning at NASA's Goddard Space Flight Center", ICES Conference 2010, (submitted for publication).

${ }^{3}$ Parrrish, K. and Cleveland, P., "Thermal System Verification and Model Validation for NASA's Cryogenic Passively Cooled James Webb Space Telescope (JWST)", ICES Conference, Paper 05ICES-236, 2005

${ }^{4}$ Nowak, Maria, "Photogrammetric metrology for the James Webb Space Telescope integrated science instrument module", Proc. SPIE Vol. 6692, 2007.

${ }^{5}$ Nowak, Maria, "Verification of the James Webb Space Telescope Integrated Science Instrument Module Cryogenic Structural Alignment Requirements via Photogrammetry” SPIE Paper 082608, 